\title{
ПЕРЕКРИТТЯ НЕБАЛАНСІВ ЗГЕНЕРОВАНОЇ ТА ПРОГНОЗОВАНОЇ ЕЛЕКТРОЕНЕРГІЇ СОНЯЧНОЮ ЕЛЕКТРОСТАНЦІЕЮ ЗА РАХУНОК СИСТЕМИ АКУМУЛЮВАННЯ ЕЛЕКТРИЧНОЇ ЕНЕРГІЇ
}

\author{
В.І. Будько ${ }^{1,2}$, д-р техн. наук, доцент, Я.В. Вайнштейн ${ }^{1}$, студент \\ ${ }^{1}$ Національний технічний університет України «Київський політехнічний інститут імені Ігоря Сікорського», \\ Факультет електроенерготехніки та автоматики, кафедра відновлюваних джерел енергії \\ 03056, просп. Перемоги, 37, м. Київ, Україна \\ ${ }^{2}$ Інститут відновлюваної енергетики НАН України, \\ 02094, вул. Гната Хоткевича, 20А, м. Київ, Україна
}

Сонячна фотоенергетика розвивається швидкими темпами, щзо приводить до появи нових важливих інженерно-технічних та науково-прикладних задач, вирішення яких є ключовим фактором стабільного розвитку не тільки даного сектору відновлюваної енергетики, а й всієї електромережі Украӥни. Однією з таких задач є підвищення показника надійності виробітку електричної енергї фотоелектростанцією та ї̈ видачі в мережу відповідно до наданого прогнозу на добу та окремо на дві години наперед. Питання стабільного виробітку актуально не лише для мережевих фотоелектростанцій, а й для фотоелектростаниій, що праџюють на часткове покриття власного споживання, коли важливо відповідати графіку спожсивання, аби не порушувати технологічні процеси у виробництві. Одним із варіантів розв 'язання цієї задачі є інтеграція різних систем акумулювання електричної енергії до складу фотоелектростанції в тому числі й електрохімічних акумуляторних батарей, що і було досліджено в даній роботі. На основі аналізу реальних даних виробітку електричної енергї протягом березня 2020 року мережевими фотоелектростаниіями, що розташовані в Херсонській області, визначені межі невідповідності виробленої електроенергї заявленому прогнозу. Встановлені відносні значення необхідної ємності електрохімічних акумуляторних батарей для забезпечення максимальної відповідності виробітку заявленому прогнозу. Розрахунок базувався на методі пошуку невідповідностей між апроксимованою моделлю та реальними даними, з подальшим обрахуванням відхилення для кожної часової точки.

Отримані графічні залежності відносного значення ємності системи акумуляторів від потужності станиії, а також графіки швидкості зміни відносного значення ємності системи та потужності станиії.

В подальшому матеріали дано. Бібл. 6, табл. 2, рис. 4.

Ключові слова: фотоелектрична батарея, сонячна електростаниія, акумуляторна батарея, смність, електроенергія.

\section{OVERLAPPING OF IMBALANCES OF GENERATED AND FORECAST ELECTRICITY BY SOLAR POWER PLANT AT THE EXPENSE OF THE ELECTRICITY ACCUMULATION SYSTEM}

\author{
V. Budko ${ }^{1,2}$, doctor of technical science, assistant professor, Y.Vainshtein ${ }^{\mathbf{1}}$, student \\ ${ }^{1}$ National Technical University of Ukraine "Igor Sikorsky Kyiv Polytechnic Institute", \\ Faculty of Electrical Power Engineering and Automatics \\ 03056, 37 Peremohy Av., Kyiv, Ukraine. \\ ${ }^{2}$ Institute of Renewable Energy of the National Academy of Sciences of Ukraine, \\ 02094, 20A Hnata Khotkevycha St., Kyiv, Ukraine
}

Solar photovoltaics is developing rapidly, which leads to the emergence of new important engineering and scientific and applied problems, the solution of which is a key factor in the sustainable development not only of this sector of renewable energy, but also the entire power grid of Ukraine. One of such tasks is to increase the reliability of electricity generation by a photovoltaic power plant and its delivery to the network in accordance with the provided forecast for the day and separately for two hours in advance. The issue of stable generation is relevant not only for network photovoltaic power plants, but also for photovoltaic power plants that work to partially cover their own consumption, when it is important to meet the consumption schedule so as not to disrupt production processes. One of the options for solving this problem is the integration of various systems of electric energy storage into the photovoltaic power plant, including electrochemical batteries, which was investigated in this paper. Based on the analysis of real data on electricity generation during March 2020 by network photovoltaic power plants located in the Kherson region, the limits of non-compliance of the generated electricity with the stated forecast were determined. The relative values of the required capacity of electrochemical batteries to ensure maximum compliance with the stated forecast. The calculation was based on the method of finding discrepancies between the approximated model and the real data, followed by the calculation of the deviation for each time point.

(C) В.І. Будько, Я.В. Вайнштейн, 2021

Відновлювана енергетика. 2021. № 4 
Graphical dependences of the relative value of the capacity of the battery system on the power of the station, as well as graphs of the rate of change of the relative value of the capacity of the system and the power of the station. Ref. 6, tab. 2, fig. 4.

Keywords: photovoltaic battery, solar power plant, rechargeable battery, capacity, electricity.

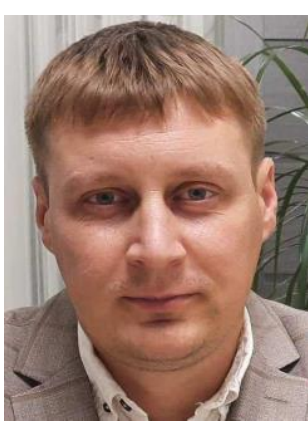

B.I. Будько V. Budko



Я.В. Вайнштейн $Y$. Vainshtein
Відомості про автора: завідувач кафедри відновлюваних джерел енергії Національного технічного університету України «Київський політехнічний інститут імені Ігоря Сікорського», доктор технічних наук

Освіта: Національний технічний університет України «Київський політехнічний інститут», спеціаліст за спеціальністю «Технічна електрохімія»

Наукова сфера: процеси перетворення та акумулювання енергії Сонця та вітру, підвищення ефективності роботи автономних та резервних систем електроживлення на основі відновлюваних джерел енергії

Публікації: понад 70 наукових праць, 4 патенти на винахід, 4 навчально-методичні роботи

ORCID: 0000-0002-6219-4221

Контакти: (050)249-25-91

e-mail: solar_budko@ukr.net

Відомості про автора: студент кафедри відновлюваних джерел енергії Національного технічного університету України «Київський політехнічний інститут імені Ігоря Сікорського»

Освіта: Національний технічний університет України «Київський політехнічний інститут», бакалавр за спеціальністю «Електроенерготехніка, Електротехніка та Електромеханіка» Наукова сфера: сонячні електростанції, системи накопичення електричної енергії, відновлювані джерела енергії.

Публікації: 6 публікацій

ORCID:0000-0002-7907-797X

Контакти: (097)578-05-56

e-mail: yaroslavvainshtein @ gmail.com
Author information: Head at the Department of Renewable Energy Sources of the National Technical University of Ukraine "Igor Sikorsky Kyiv Polytechnic Institute", Doctor of Technical Sciences

Education: National Technical University of Ukraine "Kyiv Polytechnic Institute", specialist in "Technical Electrochemistry"

Research area: Processes of transformation and accumulation of energy of the Sun and wind; Improving the efficiency of autonomous and backup power supply systems based on renewable energy sources

Publications: more than 70 scientific works, 4 patents for inventions, 4 educational and methodical works

ORCID: 0000-0002-6219-4221

Contacts: (050) 249-25-91

e-mail: solar_budko@ukr.net

Author information: Student of the Department of Renewable Energy Sources of the National Technical University of Ukraine "Kyiv

Polytechnic Institute named after Igor Sikorsky", Doctor of Technical Sciences

Education: National Technical University of Ukraine "Kyiv Polytechnic Institute", Bachelor's degree in "Electrical Engineering, Electrical Engineering and Electromechanics"

Research area: Solar power plants, Electric energy storage systems, renewable energy sources

Publications: 6 publications

ORCID: 0000-0002-7907-797X

Contacts: (097) 578-05-56

e-mail: yaroslavvainshtein@gmail.com

Перелік використаних позначень та скорочень:

$a$ - шукана величина відносної ємності BESS;

$P$ - встановлена потужність станції;

$f(x)_{\text {aprox }}$ - значення кривої апроксимації;

СЕС - сонячні електростанція;

$f(x)$ - значення кривої генерації реальних даних;

АКБ - акумуляторна батарея;

$n$ - кількість піків та падінь генерації;

BESS - battery energy storage system.

Вступ. Великий потенціал енергії енергетичного переходу України до 2050» [1], що сонячного випромінювання, 3 одного боку, та передбачає до 2050 року досягти $70 \%$ частки перспективні плани «Концепції «Зеленого» ВДЕ у виробництві електричної енергії, з яких до 
$15 \%$ має складати виробництво електроенергії за рахунок дахових СЕС в домогосподарстві та бізнесі, а також збільшення децентралізованого електропостачання, 3 іншого боку, стимулюють потужний розвиток сонячної енергетики в Україні. Разом 3 прийнятими планами була затверджена й основна політика стимулювання розвитку відновлюваних джерел - «зелений» тариф. Хоча «зелений» тариф і допоміг країні вийти на необхідний рівень впровадження технологій відновлюваної енергетики, проте повномасштабна політика реформування енергосистеми була відсутня, тому постала необхідність впровадження заходів регулювання розвитку ВДЕ шляхом проведення «зелених» аукціонів та прогнозування виробітку електричної енергії. Зелені аукціони створюють умови рівної конкуренції та загалом дають змогу зробити ринок ВДЕ більш прозорим, що дозволяє підвищити не тільки якість побудованих станцій, а й забезпечує баланс інтересів на енергетичному ринку. Прогнозування виробітку електричної енергії несе більш технічний характер та направлене на дотримання балансу між споживанням та виробництвом електричної енергії. Невідповідність між прогнозованим рівнем генерації та реально отриманим спричиняє так звані небаланси. Залежно від потужності СЕС встановлюється відповідний абсолютний рівень максимально можливого небалансу, вихід за який призводить до покарання шляхом накладання штрафних санкцій.

Мінливість погодних умов та неможливість ïx точного прогнозування $\epsilon$ основною причиною небалансів, адже виробіток СЕС залежить від багатьох природних факторів: рівня інтенсивності сонячного випромінювання, вологості повітря, швидкості вітру і т. п. Зараз існує багато підходів до прогнозування, проте класифікувати їх можна за двома параметрами: самим методом прогнозування та часовим горизонтом прогнозування. Методи прогнозування загалом надають більш-менш схожу інформацію, проте залежно від часового горизонту, до якого цей метод застосовується, 3'являються суттєві відмінності в прогнозованих величинах. Найточнішим є внутрішньогодинний метод прогнозування, який дає змогу надавати точну інформацію в короткі проміжки часу5-60 хвилин. Однак він не є допустимим в умовах енергоринку України, адже прогноз потрібно надавати «на добу наперед».

Використання найсучасніших методів та засобів прогнозування не допомагає уникнути небалансів, тому необхідний пошук додаткового балансуючого джерела. Цим джерелом здебільшого може бути система накопичення електричної енергії (BESS). Однак відкритим питанням залишається розрахунок оптимальної ємності такої системи 3 урахуванням всіх необхідних параметрів. Існує декілька фундаментальних підходів до розрахунку ємності BESS, проте вони мають застосування лише в невеликих господарських СЕC та не $\epsilon$ раціональними для великих СЕС мегаватного класу. Для таких СЕС застосовують два методи щодо розрахунку ємності BESS: basic level та peak shaving.

Метод basic level характеризується відсотковою залежністю ємності запасу від встановленої потужності СЕС. Даний метод в кінцевому підсумку дозволяє отримати велику систему запасу ємності, що дозволить перекривати небаланси, проте дана система не буде оптимальною.

Метод peak shaving полягає в аналізі річного прогнозу виробітку електричної енергії СЕС та виявленню піків виробітку. Відповідно до отриманих піків виробітку роблять вибірку, згідно з якою обирають медіану цієї вибірки, яка 
й відповідатиме необхідній ємності АБ. Даний метод має також і інші підходи до аналізу піків, проте жоден з них не в змозі в кінцевому підсумку гарантувати перекриття небалансів, проте отримана система буде максимально наближена до оптимальної.

\section{Постановка завдання. Відсутність} систематизованого практичного підходу до розрахунку ємності системи накопичення енергії призводить до неоптимального підбору BEES. Важливим питанням також залишається метод визначення ємності BESS та моделювання роботи СЕС. Метою даної статті $є$ розробка методу розрахунку системи BESS при врахуванні параметрів географічного розташування, а саме аналізі річного розподілу рівня сонячної інсоляції.

Результати дослідження. Як об'єкт дослідження було вибрано існуючі станції, що працюють за «зеленим» тарифом. Всі сонячні електростанції розташовані в Херсонській області, що дозволить прийняти рівність кліматогеографічних умов для всіх об’єктів дослідження. При цьому варто вказати, що всі станції обладнані системою моніторингу та працюють вже більше року, що дає змогу отримати погодинні дані генерації з детальної графікою, яка відображає усі зміни протягом сонячного дня.

Система моніторингу фіксує значення рівня генерації кожні 15 хвилин. Оскільки вибрані станції працюють за «зеленим» тарифом, то за рахунок синхронізації мережевого інвертора 3 зовнішньою мережею одним з факторів впливу на генерацію $є$ наявність живлення цієї самої мережі. Подібні ситуації з втратою генерації не будуть враховуватися при аналізі генерації, оскільки в цьому разі наслідки, а саме штрафи, за втрату (падіння) генерації не стосуються виробника електроенергії з СЕС. Також не враховуються випадки, коли виникали проблеми 3 устаткуванням: помилки або вихід 3 ладу інвертора та перенапруги, які призвели до спрацювання системи захисту або захисту самого інвертора. Отже аналізований рівень генерації та його характер, на основі якого вибиратиметься BEES, залежить лише від погодних умов, як-от: хмарність, дощ, температура, вологість, швидкість вітру.

Аналізу підлягають станції потужністю 17, 20, 25 та 30 кВт на базі інвертора (потужність за $\mathrm{AC),} \mathrm{рівень} \mathrm{потужності} \mathrm{сонячних} \mathrm{панелей}$ (потужність за DC) при цьому йде більшим на 1,2, що пов'язано 3 умовою оптимальної роботи інвертора. В даній статті також аналізується генерація лише за березень 2020 року.

Система моніторингу виводить дані інфографікою у вигляді графіку з відображенням точок рівня генерації кожні 15 хвилин. Відповідний графік представлений на рис. 1.

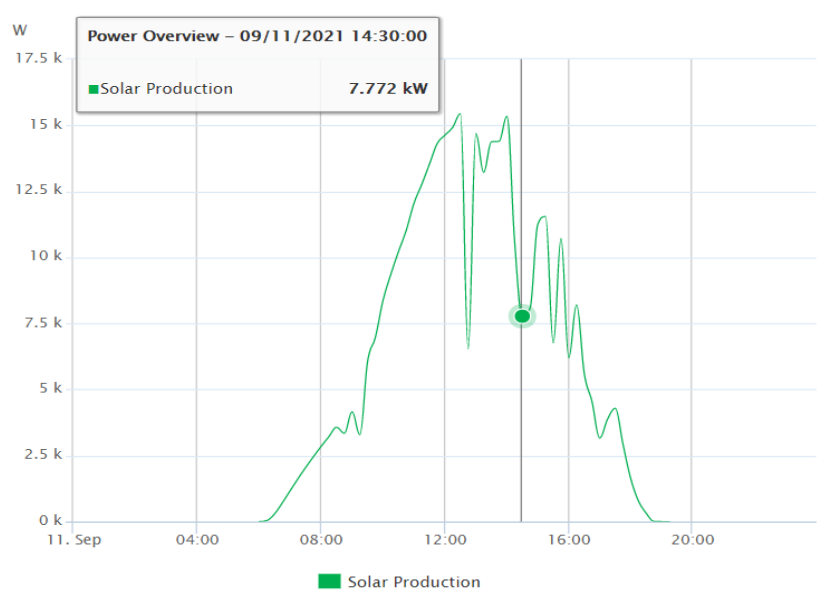

Рис. 1. Графік генерації з системи моніторингу

Fig. 1. Generation graph of monitoring systems

Відповідні дані генерації заносились до таблиці, після чого підлягали аналізу. Суть методу полягала в побудові графіку та апроксимації задля досягнення ідеальної кривої генерації. 

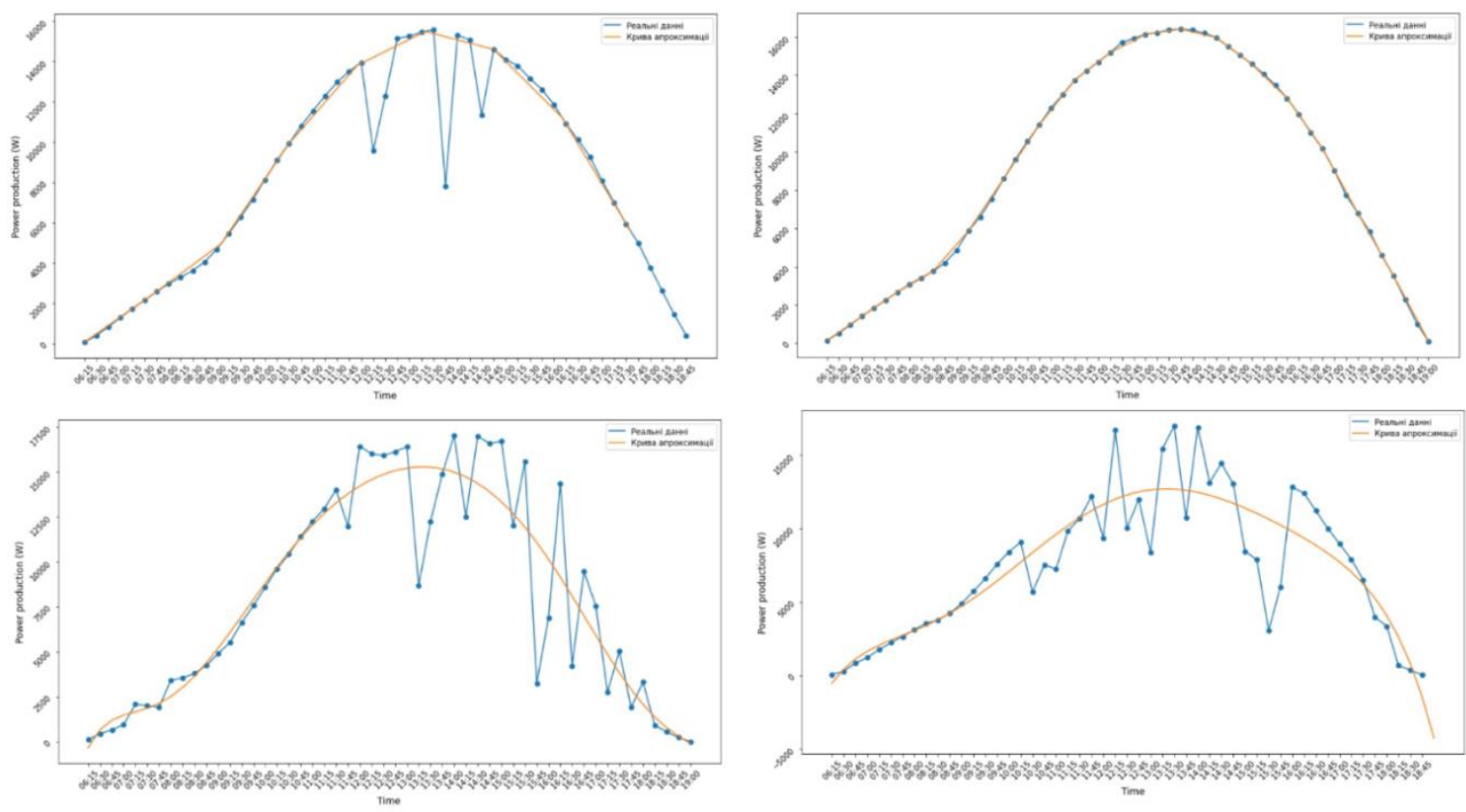

Рис. 2 Приклад графіків генерації та апроксимації

Fig. 2. Example of generation and approximation graphs

Далі йде пошук локальних мінімумів та максимумів генерації (падіння та піки) та розрахунок середнього значення похибки між відповідними реальними даними та даними кривої апроксимації. Ці дії повторюються для кожного дня, після чого все зводиться до єдиної бази похибок, з якої методом знаходження середньої величини ми й отримуємо шукану величину ємності BESS у відсотковому значенні відносно потужності станції.

Математично описаний метод виглядає так:

$$
a=\frac{\frac{\sum_{i=0}^{n} \mid f(x) \text { aprox }-f(x) \mid}{n}}{P} \cdot 100 \%,
$$

де $a$ - шукана величина відносної ємності BESS; $f(x)_{\text {aprox }}$ - значення кривої апроксимації; $f(x)$ значення кривої генерації реальних даних; $n-$ кількість піків та падінь генерації; $P$ - встановлена потужність станції.

Потрібно зауважити, що при переході від відносного значення до абсолютного потрібно враховувати втрати під час розряджання та заряджання акумуляторної батареї, умови іiі експлуатації та розрядні характеристики. Це приведе до отримання такої формули ємності BESS:

$$
C=a \cdot P \cdot k,
$$

де $k=1,5$ - коефіцієнт врахування виробничих та експлуатаційних особливостей, розрядних характеристик та втрат під час розрядження та заряджання акумуляторної батареї.

Розрахувавши відповідне значення $a$ для кожної зі станцій, які розглядались, до табл. 1 занесли отримані величини.

\section{Таблиця 1. Отримані значення $a$}

Table 1. The resulting values of a

\begin{tabular}{|c|c|c|c|c|}
\hline$P$, кВт & 17 & 20 & 25 & 30 \\
\hline$a, \%$ & 14,43 & 15,65 & 16,32 & 16,88 \\
\hline
\end{tabular}




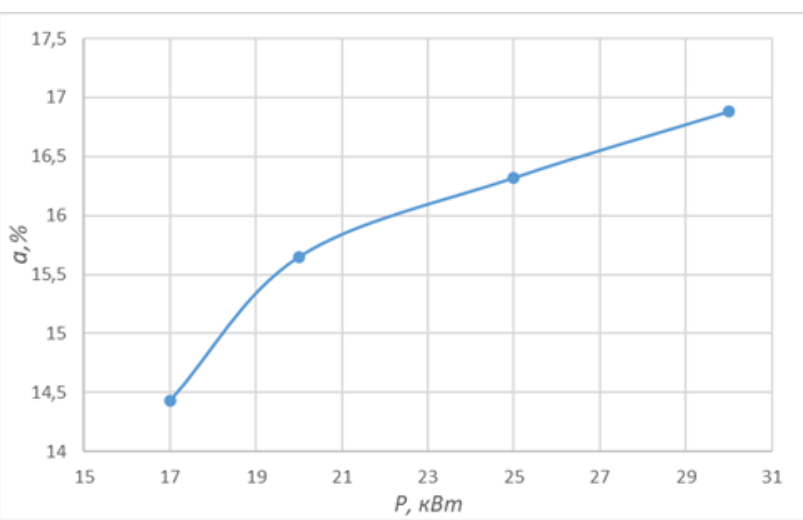

Рис. 3. Залежність $\boldsymbol{a}$ від $\boldsymbol{P}$

Fig. 3. Dependence of a on $P$

Аналізуючи отриманий графік (рис. 3), можна говорити про певну залежність, а саме про те, що зі збільшенням потужності станції збільшується відсоткова необхідна ємність BESS. Проте якщо взяти до уваги крок збільшення потужності відносно базового значення та відповідний крок збільшення відсоткового значення BESS, то отримаємо такі значення (табл. 2).

Таблиця 2. Швидкість збільшення $P$ та $a$ відносно першого значення

Table 2. The rate of increase of $P$ and a relative to the first value

\begin{tabular}{|c|c|c|c|}
\hline$\Delta P, \%$ & 1,18 & 1,47 & 1,76 \\
\hline$\Delta a, \%$ & 1,08 & 1,13 & 1,17 \\
\hline
\end{tabular}

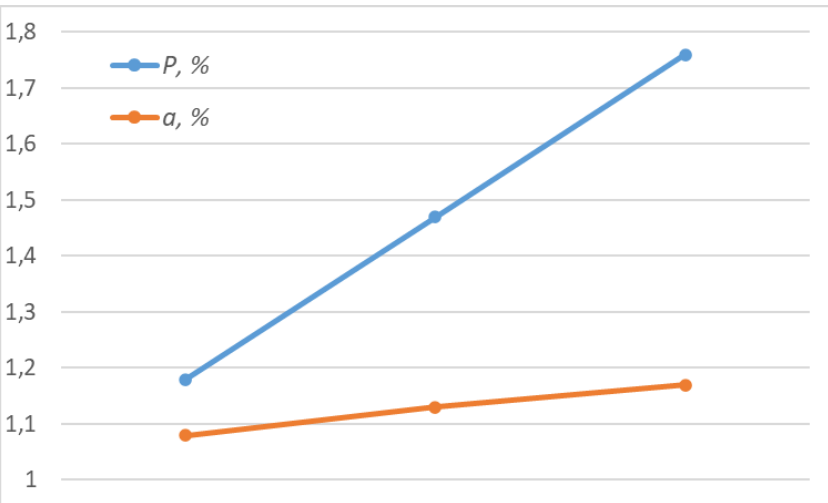

Рис. 4. Швидкість збільшення $P$ та $\boldsymbol{a}$ відносно першого значення

Fig. 4. The rate of increase of $P$ and a relative to the first value.
Як видно на рис. 4, потужність збільшується швидше, ніж відсоткова ємність BESS, що пояснюється або недостатньою аналітикою, оскільки аналіз був проведений для невеликої кількості СЕС та лише для одного місяця року, або є дійсним законом, тобто незалежністю відносної ємності BESS від потужності станції.

Висновки. Отримані результати показують, що ємність системи BESS має бути на рівні 15-17 \%. Це дасть змогу перекривати більшу частину стохастичних піків та падіння генерації, а також загалом забезпечувати буфер у 10 \%, щоб уникати штрафів за небаланси. Надалі потрібно проаналізувати відповідні станції для кожного дня року, тим самим збільшивши діапазон аналізованих даних, що дасть змогу отримати точні значення відсоткового значення BESS.

1. Концепція «Зеленого» енергетичного переходу України до 2050. Міністерство енергетики та захисту довкілля, 2020. URL: https://mepr.gov.ua/news/34424.html. (дата звернення: 05.08.2021)

2. István Táczi. Overview of the Energy Storage Possibilities to Support the Electrical Power System. Research Paper to assist the ERRA Licensing and Competition Committee. 2016.

3. Alexandre Oudalov, Antoine Béguin, Rachid Cherkaoui. Sizing and Optimal Operation of Battery Energy Storage System for Peak Shaving Application. Conference Paper. 2007.

4. Tsung-Ying Lee; Nanming Chen. Determination of optimal contract capacities and optimal sizes of battery energy storage systems for Timeof-Use rates industrial customers. IEEE Transactions on Energy Conversion. Energy Conversion, 1995. Vol. 20(3). Pp. 562-568.

5. Even A., Neyens J., Demouselle A. Peak shaving with batteries, 12th International Conference on Electricity Distribution, 1993.

6. Energy Storage Trends and Opportunities. ESMAP. 2017. URL: https://www.esmap.org/node/57868 (дата звернення: 11.09.2021) 


\section{REFERENCES}

1. Kontseptsiia «Zelenoho» enerhetychnoho perekhodu Ukrainy do 2050. [The concept of "Green" energy transition of Ukraine until 2050]. Ministry of Energy and Environmental Protection.-2020.

esmap.org.

URL:

https://www.esmap.org/node/57868. [in Ukrainian].

2. István Táczi. Overview of the Energy Storage Possibilities to Support the Electrical Power System. Research Paper to assist the ERRA Licensing and Competition Committee. 2016. [in English].

3. Alexandre Oudalov, Antoine Béguin, Rachid Cherkaoui. Sizing and Optimal Operation of Battery Energy
Storage System for Peak Shaving Application. Conference Paper. 2007. [in English].

4. Tsung-Ying Lee, Nanming Chen. Determination of optimal contract capacities and optimal sizes of battery energy storage systems for Timeof-Use rates industrial customers. IEEE Transactions on Energy Conversion. Energy Conversion, 1995. Vol. 20(3). Pp. 562-568. [in English].

5. Even A., Neyens J., Demouselle A. Peak shaving with batteries, 12th International Conference on Electricity Distribution, 1993. [in English].

6. Energy Storage Trends and Opportunities. ESMAP, 2017. URL: https://www.esmap.org/node/57868 [in English].

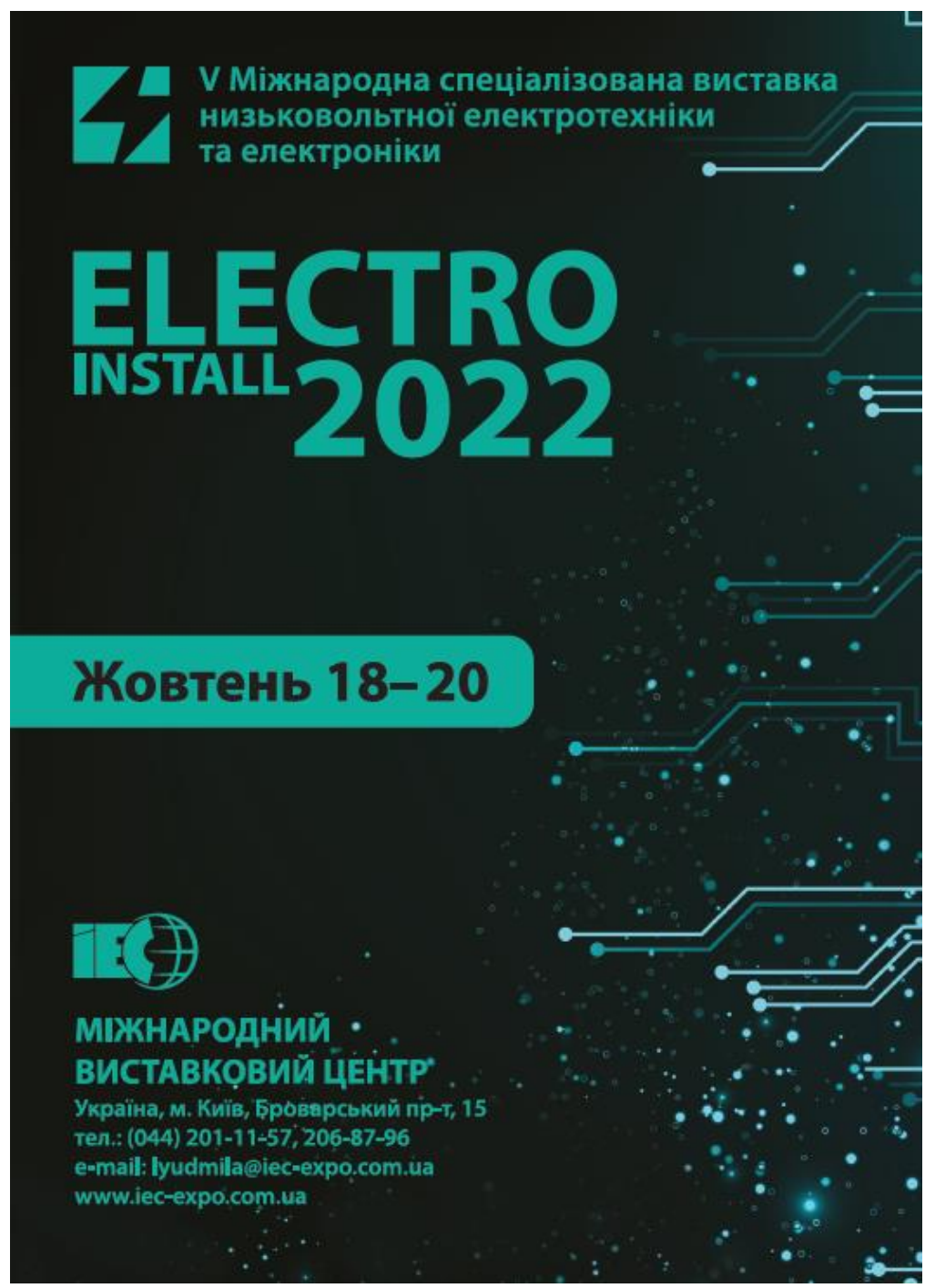

